\title{
FREQUENCY OF STROKE TYPES AT AN EMERGENCY HOSPITAL IN NATAL, BRAZIL
}

\author{
Antonio N.N. Martins Jr', Marcelo M. de Figueiredo', Orlandil D. Rocha', \\ Maria A. F. Fernandes', Selma M.B. Jeronimo', Mario E. Dourado Jr',3
}

\begin{abstract}
We performed a cross-sectional study of stroke type frequency at a local emergency hospital, in Natal, Brazil. The sample consisted of all patients who were admitted to an emergency hospital with a presumptive diagnosis of stroke. Of the 416 patients, 328 were studied, 88 were excluded for not meeting inclusion criteria, $74.7 \%(n=245)$ had ischemic stroke $17.7 \%(n=58)$ had intracerebral hemorrhage, $7.6 \%(n=25)$ had subarachnoid hemorrhage; 173 were men $(52.7 \%)$. Mean age was 64.1 years. The intrahospital mortality rate was $10.2 \%, 17.2 \%$ and $36 \%$ for ischemic stroke, intracerebral hemorrhage and subarachnoid hemorrhage, respectively. The most prevalent modifiable risk factor was hypertension for ischemic stroke (67.6\%) and hemorrhage stroke (57.8\%). Logistic regression analysis identified diabetes $(\mathrm{OR}=3.70 ; \mathrm{Cl}=1.76-7.77)$ as independent risk factor for ischemic stroke. The ischemic stroke was most common type of stroke. Hypertension and diabetes were important risk factors for stroke.
\end{abstract}

KEY WORDS: stroke, Brazil, hypertension.

Freqüência dos tipos de acidente vascular cerebral em hospital de emergência, Natal, Brasil

RESUMO - Realizamos um estudo de prevalência para determinar a freqüência dos tipos de acidente vascular cerebral (AVC) num hospital de urgência de Natal. Estudaram-se todos os pacientes que foram admitidos no hospital de urgência com diagnóstico presuntivo de AVC. Dos 416 pacientes, 328 foram estudados, 88 foram excluídos por não cumprirem os critérios de inclusão, $74,7 \%(n=245)$ tiveram AVC isquêmico, $17,7 \%(n=58)$ hemorragia intracerebral e 7,6\% ( $n=25)$ hemorragia subaracnóidea. O gênero mais prevalente foi o masculino $(52,7 \%)$. A média de idade foi 64,1 anos. A letalidade intra-hospitalar foi de $10,2 \%$, $17,2 \%$ e $36 \%$ para o tipo isquêmico, hemorrágico e hemorragia subaracnóide, respectivamente. 0 principal fator de risco modificável foi a hipertensão arterial sistêmica (HAS) para AVC isquêmico $(67,6 \%)$ e AVC hemorrágico $(57,8 \%)$. A regressão logística identificou diabetes como fator de risco independente para AVC isquêmico $(O R=3,70 ; I C=1,76-7,77)$. $O A V C$ isquêmico foi o tipo mais comum. HAS e diabetes foram importantes fatores de risco.

PALAVRAS-CHAVE: AVC, Brasil, hipertensão.

Stroke has become an increasingly important health problem worldwide. There are about 5.5 million yearly deaths and an estimated loss of 49 million disability-adjusted life years worldwide ${ }^{1-4}$. Hypertension and age are the main risk factors for the different types of stroke, which include ischemic (IS), intracerebral hemorrhage (ICH), and subarachnoid hemorrhage (SAH). The management strategies of these ailments are distinct, since they are heterogenous diseases ${ }^{5}$. There has been a decreasing trend in incidence and mortality from stroke in the USA and Europe ${ }^{6,7}$. In contrast, its incidence has increased in developing countries, which may be due to the rapid aging of the population, and increased prevalence of stroke risk factors resulting from change in diet, sedentary life- style and diabetes ${ }^{2}$. Lavados et al. showed a raw annual stroke incidence of 95.8 per 100 ooo inhabitants in Chile ${ }^{8}$. Studies have also reported large geographical variation in stroke epidemiology in the last decades. Japan has a higher stroke incidence than other developed countries and this could be related to genetic and environmental factors'.

The epidemiology of strokes in Brazil has changed in the last 30 years as the country has become more urbanized, with a shift from infectious to more chronic diseases ${ }^{10}$. Stroke and coronary diseases are currently the main cause of death in Brazil, followed by cancer $^{11}$. A recent study showed a decrease of stroke mortality in Brazil'12.

The purpose of the current study was to deter-

Monsenhor Walfredo Gurgel Hospital, Natal RN, Brazil: 'Department of Biochemistry, Center for Bioscience; ${ }^{2}$ Department of Dentistry, Health Graduate Program, Health Science Center; ${ }^{3}$ Universidade Federal do Rio Grande do Norte, Natal RN, Brazil.

Received 27 April 2007, received in final form 1 August 2007. Accepted 1 September 2007.

Dr. Mario E. Dourado - Rua Marcílio Furtado 2042 - 59063-360 Natal RN - Brasil. E-mail: medourado@digi.com.br 
mine the frequency, type and risk factors for stroke in a northeastern state Natal, Brazil.

\section{METHOD}

We performed a cross-sectional study, in which we analized 416 records of patients who were admitted to the emergency room of the main public hospital of urgency of Natal, state of Rio Grande do Norte (Monsenhor Walfredo Gurgel Hospital).

Stroke was defined as a rapid development of clinical signs of focal disturbance, occasionally global, in cerebral function, lasting more than 24 hours or leading to death without any other apparent cause of vascular origin. Patients with stroke diagnosed by clinical and computer tomography (CT) were included, independent of gender or age. All patients who had been admitted for more than 24 hours and met inclusion criteria were eligible for enrollment.

Patients with head trauma, transient ischemic attack and silent brain infarction were excluded from the study.

Charts of patients diagnosed with stroke between December 2004 and May 2005 were reviewed retrospectively. The data obtained from the charts included: type of stroke, CT scan results, other exams (carotid duplex scans, catheter angiography, transthoracic echocardiography) and clinical outcome. We also reviewed data on the following risk factors: age, gender, previous stroke, familiar history, hypertension (a history of treated hypertension or current use of antihypertensive medication); diabetes (a history of diabetes or current treatment for diabetes mellitus), coronary-artery disease (history of angina, acute myocardial infarction, or coronary revascularization); congestive heart failure (history of or current treatment for congestive heart failure); atrial fibrillation (known previous atrial fibrillation or current treatment for atrial fibrillation); hypercholesterolemia (current treatment for hypercholesterolemia); smoking (current smoker); and alcohol intake.

The classification of stroke type was based on clinical presentation and was confirmed by CT. The "TOAST" diagnostic criteria $^{13}$ was used to classify IS subtypes. Briefly, 5 categories were described: (1) large artery atherosclerosis, when there was stenosis $>50 \%$ or occlusion of a major brain artery, presumably attributable to atherosclerosis; (2) cardioembolic infarcts, where cardio sources included evidence of atrial fibrillation, recent ( $<3$ months) myocardial infarction, and infective endocarditis, defined as valvular lesions on echocardiogram and positive blood cultures; (3) lacunar infarcts, when a patient had a history of hypertension or diabetes mellitus with a clinical lacunar syndrome and an ischemic lesion not $>15 \mathrm{~mm}$ or a normal CT and no other cause of infarct, for example, significant stenosis or atrial fibrillation; (4) other determined etiology; and (5) undetermined etiology, in cases of incomplete evaluation.

ICH of hypertensive origins was considered in hypertensive patients with a hemorrhagic area in the basal nucleus and thalamus. SAH was regarded as cases with acute onset of severe headache, sometimes associated with loss of consciousness, seizures, or focal neurological signs not associated with trauma, and a brain CT scan showing subarachnoid or cisternal high attenuation and aneurism defined by cerebral arteriography, as well as the diagnosis of possible venous infarct. ICH due to arteriovenous malformations was diagnosed by cerebral arteriography. Stroke was considered undetermined when there was no confirmation of stroke subtype.

Statistical analysis was performed using SPSS version 10.0. The factors were analyzed descriptively by means of absolute numbers and proportions. The Odds Ratio (OR) of variables related to risk factors were determined. The association between the stroke type and risk factors was calculated by the Pearson Chi-Square test and by multiple logistic regression analysis. The Hosmer-Lemeshow test was used to verify the goodness-of-fit of the model.

The protocol (CEP-UFRN 80-05) was reviewed and approved by the Ethics Committee of Universidade Federal do Rio Grande do Norte and followed Brazilian guidelines for human research, resolution 196/96. The certificate of approval (CAAE) is 0046.0.051.000-05.

\section{RESULTS}

Between December 2004 and May 2005, 4932 patients were admitted to the hospital; of these, $416(8.4 \%)$ presented with symptoms suggestive of stroke. After clinical and image examinations, 88 patients were excluded for not meeting inclusion criteria. Records were reviewed for 328 patients [ 173 men $(52.7 \%)$ and 155 women (47.3\%)]. The average age for both groups was $64.08 \pm 16.31$ years. The total number of hemorrhagic strokes (HS) was 83 (25.3\%), which included $\mathrm{ICH}$ in 58 cases (17.7\%) and $\mathrm{SAH}$ in $25(7.6 \%)$. Of these, $36(43.4 \%)$ were men and $47(56.6 \%)$ were women; mean age was $57.10 \pm 15.51$ years. The number of patients with IS was 245 (74.7\%), of whom 137 $(56 \%)$ were men and 108 (44\%) were women, with a mean age of $65.71 \pm 15.67$ years. Stroke was more frequent in older patients, with the exception of SAH, which was more common in younger patients. SAH was also more frequent in women (Table 1 ).

Main risk factors for developing stroke - Despite the limited data present in the medical charts, it was possible to determine a number of risk factors. Hypertension was a major risk for stroke, both for HS (57.8\%) and for IS (67.6\%). Other risk factors included older age, male gender, previous personal and family history of stroke (Table 2).When we performed multiple logistic regression analysis, diabetes and male gender were associated with risk of IS, as presented in Table 3.

Stroke etiology - There was a lack of complementary studies. Only ninety electrocardiograms were recorded, while echocardiograms were performed on 12 patients and carotid duplex scans were carried out on 8 individuals. All patients diagnosed with SAH underwent cerebral angiography. 
Table 1. Distribution of patients with Ischemic, cerebral hemorrhage and subarachnoidal hemorrhage strokes according to age, type of stroke and gender.

\begin{tabular}{|c|c|c|c|c|c|c|}
\hline \multirow[b]{3}{*}{ Patient characteristics } & \multicolumn{6}{|c|}{ Stroke type } \\
\hline & \multicolumn{2}{|c|}{ Ischemic } & \multicolumn{2}{|c|}{ Cerebral hemorrhage } & \multicolumn{2}{|c|}{ Subarachnoidal hemorrhage } \\
\hline & $\mathrm{N}$ & $\%$ & $\mathrm{~N}$ & $\%$ & $\mathrm{~N}$ & $\%$ \\
\hline Gender & 108 & 44 & 27 & 46 & 21 & 84 \\
\hline Female & 137 & 56 & 31 & 54 & 4 & 16 \\
\hline \multicolumn{7}{|l|}{ Male } \\
\hline \multicolumn{7}{|l|}{ Age } \\
\hline$<44$ & 20 & 8.2 & 4 & 6.9 & 8 & 32 \\
\hline $44-65$ & 84 & $34 \cdot 3$ & 23 & 39.6 & 11 & 44 \\
\hline$>65$ & 130 & 53.1 & 30 & 51.7 & 4 & 16 \\
\hline Undefined age & 11 & 4.4 & 1 & 1.8 & 2 & 8 \\
\hline
\end{tabular}

Table 2. Risk factors accordingly to the stroke type.

\begin{tabular}{|c|c|c|c|c|c|c|c|}
\hline \multirow[b]{2}{*}{ Risk factor } & \multicolumn{2}{|c|}{ Ischemic stroke* } & \multicolumn{2}{|c|}{ Hemorrhagic stroke } & \multirow{2}{*}{$\begin{array}{l}\text { Odds } \\
\text { ratio }\end{array}$} & \multirow{2}{*}{$\begin{array}{c}\text { Confidence } \\
\text { interval }\end{array}$} & \multirow[b]{2}{*}{$\mathrm{p}^{\dagger}$} \\
\hline & $\mathrm{N}^{\ddagger}$ & $\%$ & $\mathrm{~N}^{\S}$ & $\%$ & & & \\
\hline \multicolumn{8}{|l|}{$\mathrm{Age}^{\#}$} \\
\hline$<44$ & 20 & 8.6 & 12 & 15 & 1 & & \\
\hline $44-65$ & 84 & 36 & 34 & 42.5 & 1.55 & $0.89-2.68$ & 0.12 \\
\hline$>65$ & 130 & 53.8 & 34 & 42.5 & 2.29 & $1.02-5.15$ & 0.044 \\
\hline \multicolumn{8}{|l|}{ Gender } \\
\hline Female & 107 & 43.9 & 47 & 56.6 & 0.6 & $0.36-1.02$ & 0.06 \\
\hline Male & 137 & 56.1 & 36 & 43.4 & & & \\
\hline Hypertension & 165 & 67.6 & 48 & 57.8 & 1.50 & $0.90-2.51$ & 0.12 \\
\hline Previous stroke & 73 & 29.8 & 21 & $25 \cdot 3$ & 1.25 & $0.71-2.21$ & 0.43 \\
\hline Diabetes mellitus & 76 & 31.1 & 9 & 10.8 & 3.70 & $1.76-7.77$ & $<0.01$ \\
\hline Family history & 56 & 22.9 & 20 & 24.1 & 0.93 & $0.52-1.67$ & 0.82 \\
\hline
\end{tabular}

*Patients presenting with venous infarct were excluded; ${ }^{\dagger}$ Chi-square test; ${ }^{\ddagger}$ Number of patient with risk factor for ischemic stroke; ${ }^{5}$ Number of patient with risk factor for hemorrhagic stroke; "Patients with unknown age were excluded.

Table 3. Logistic-regression analysis between stroke type and risk factors.

\begin{tabular}{lcccccc}
\hline Risk factor & $\begin{array}{c}\text { Odds } \\
\text { ratio }\end{array}$ & $\begin{array}{c}\text { Confidence } \\
\text { interval }\end{array}$ & $\mathrm{p}$ & $\begin{array}{c}\text { Odds ratio } \\
\text { adjusted }\end{array}$ & $\begin{array}{c}\text { Confidence } \\
\text { interval }\end{array}$ & $\mathrm{p}$ \\
\hline $\begin{array}{l}\text { Age }^{\dagger} \\
\quad<44\end{array}$ & 1 & & & & & \\
$\quad 44-65$ & 1.548 & $0.89-2.679$ & 0.12 & 1.45 & $0.89-2.68$ & 0.2 \\
$\quad>65$ & 2.294 & $1.02-5.153$ & 0.044 & 1.48 & $1.02-5.15$ & 0.38 \\
$\begin{array}{l}\text { Gender } \\
\quad \text { Female }\end{array}$ & 0.612 & $0.37-1.02$ & 0.06 & 1.97 & $1.14-3.40$ & 0.015 \\
$\quad \begin{array}{l}\text { Male } \\
\text { Hypertension }\end{array}$ & 1.504 & $0.9-2.51$ & 0.12 & 1.22 & $0.90-2.51$ & 0.49 \\
Diabetes mellitus & 3.698 & $1.76-7.773$ & $<0.01$ & 3.95 & $1.76-7.77$ & $<0.01$ \\
\hline
\end{tabular}

${ }^{\dagger}$ Patients with unknown age were excluded; Hosmer-Lemeshow test: $p=0,984$.

Thus, in the majority of the cases, the etiology was undefined for both ischemic type (64.5\%) and hemorrhagic type ( $45.8 \%)$. When it was possible to determine the cause, large-artery atherosclerosis (25.3\%) was the most prevalent, followed by cardioembolic infarcts and lacunar infarcts (both with $4.9 \%$ ) and finally by venous infarct (0.4\%) in the IS (Table 4 ). Similarly, hypertension (38.6\%), followed by aneu- 
Table 4. Etiology of Ischemic stroke.

\begin{tabular}{lcc}
\hline & \multicolumn{2}{c}{ Ischemic stroke } \\
\cline { 2 - 3 } Etiology & $\mathrm{N}$ & $\%$ \\
\hline Undefined & 158 & 64.5 \\
Large artery disease & 62 & 25.3 \\
Cardioembolic & 12 & 4.9 \\
Lacunar infarction & 12 & 4.9 \\
Venous infarction & 1 & 0.4 \\
Total & 245 & 100 \\
\hline
\end{tabular}

rism (12.0\%) and arteriovenous malformations (3.6\%) were the most prevalent stroke etiologies for hemorrhagic type (Table 5).

Mortality - Of the 328 patients, $44(13.4 \%)$ died during hospitalization; the case-fatality rate in the first 30 days poststroke was $10.4 \%$. Intrahospital rate was $36 \%$ for SAH, $17.6 \%$ for ICH and $10.2 \%$ for IS.

\section{DISCUSSION}

Stroke has increased in Brazil as the country has become more urbanized. The cases reviewed here showed that IS is the most frequent type of stroke, followed by ICH and SAH. These findings are similar to those described in other countries ${ }^{9,14}$. A review of stroke in South America showed a higher proportion of hemorrhagic stroke than in the population described here ${ }^{15}$. A similar IS age group was seen in Argentina ${ }^{15}$. We observed that patients with hemorrhagic stroke were about seven years older than those of a study conducted in Dakar'.

Risk factors for developing strokes are well recognized, with age and hypertension the main factors. The status of the hypertensive disorder has been shown to be controlled by therapy, diet and exercise, which together lead to a reduction in the incidence of new strokes ${ }^{16}$. Dietary habits in Brazil have changed substantially in the past few decades and this has led to a substantial increase in obesity ${ }^{17}$. The relationship between stroke risk and blood pressure level is linear, where for each $10 \mathrm{~mm}$ rise in blood pressure, the risk of stroke increases $30 \%{ }^{18}$. There is clear evidence that treatment of the underlying hypertensive disorder, including the use of multidrug therapy, prevents stroke ${ }^{19}$. In the PROGRESS study, it was established that controlling blood pressure after IS has become the fourth main prevention strategy ${ }^{20,21}$, along with aspirin and endarterectomy. Patients with atrial fibrillation seem to improve with warfarin ${ }^{19}$. A meta-analysis performed in 2003 showed that the main risk fac-
Table 5. Etiology of hemorrhagic stroke.

\begin{tabular}{lcc}
\hline & \multicolumn{2}{l}{ Hemorrhagic stroke } \\
\cline { 2 - 3 } Etiology & $\mathrm{N}$ & $\%$ \\
\hline Undefined & 38 & 45.8 \\
Hypertension & 32 & 38.6 \\
Aneurism & 10 & 12.0 \\
AVM* & 3 & 3.6 \\
Total & 83 & 100 \\
\hline
\end{tabular}

*AVM Arteriovenous malformations; ${ }^{\dagger}$ Hemorrhagic stroke represents intracerebral hemorrhage and subarachnoid hemorrhage.

tors for ICH were male gender, age, hypertension and alcohol intake. High cholesterol levels seem to be a protective factor against $\mathrm{HS}$, but individuals with this condition are more prone to develop $\mathrm{IS}^{22}$. Our findings showed that hypertension was the main risk factor for stroke. Our study population belongs to a low-status social group, which has little access to multidrug therapy to treat the underlying hypertension. Diabetes was present in $31.1 \%$ of the patients with IS and in $10.8 \%$ with HS, results similar to those of a previous study conducted in Brazil ${ }^{23}$. Studies show that diabetes is more frequent in individuals with stroke in developing countries, when compared to those in developed countries ${ }^{8,23,24}$. Aging, increase in obesity, diabetes and hypertension are considered the main risk factors involved in the higher incidence of stroke in the developing countries ${ }^{8,9}$. The limited amount of data recorded on the patients' charts unabled us to infer associations between stroke and other important risk factors such as alcoholism and hypercholesterolemia.

Most of the patients in our study were classified as undetermined because of the lack of definite identification of stroke subtypes, a problem also reported elsewhere in Brazil ${ }^{23}$ and in Senegal'. This is contrary to what is observed in developed countries and other Brazilian regions, where diagnosis can be better ascertained ${ }^{9,25}$. Our data showed that only a minority of the patients presented with IS as a consequence of some cardiac involvement. The lack of access to transoesophageal echocardiography leads to difficulty in determining stroke etiology, and may result in an underestimation of cardiac lesions as the primary cause of strokes. Premature discharge and lack of complementary exams are among the factors that might explain the high frequency of undetermined causes in our study. It also suggests that stroke is being neglected ${ }^{3}$.

The case-fatality rate in the first 30 days poststroke of our study population was $10.4 \%$. Patients presenting with SAH had the highest mortality rate. Overall, this rate was lower than that reported worldwide in 
the first 30 days poststroke ${ }^{9}$. This finding might reflect our inclusion criteria, in which we excluded patients who died in hospital within 24 hours of admission or who died at home. Thus, the final diagnosis of the most severe cases was not determined and they were not included in this analysis. Another reason might be the younger mean age of our population in comparison to other regions of Brazil $^{12}$.

In conclusion, our study has important practical implications. Smoke cases must be more thoroughly investigated by means of complementary examinations, in order to determine its etiology and, if necessary, initiate secondary prophylaxis. Therefore, public health policies aimed at promoting measures to reduce hypertension and obesity should lead to decreased mortality and morbidity from strokes.

\section{REFERENCE}

1. Sagui E, M'Baye PS, Dubecq C, et al. Ischemic and hemorrhagic strokes in Dakar, Senegal: a hospital-based study. Stroke 2005;36:1844-1847.

2. Feigin VL. Stroke epidemiology in the developing world. Lancet 2005; 25;365:2160-2161.

3. Lotufo PA. Stroke in Brazil: a neglected disease. Sao Paulo Med J 2005;123:3-4.

4. Cox AM, McKevitt C, Rudd AG, Wolfe CD. Socioeconomic status and stroke. Lancet Neurol 2006;5:181-188.

5. Bonita R. Epidemiology of stroke. Lancet 1992;339:342-344.

6. Bonita R, Stewart A, Beaglehole R. International trends in stroke mortality: 1970-1985. Stroke 1990;21:989-992.

7. Truelsen T, Piechowski-Jozwiak B, Bonita R, Mathers C, Bogousslavsky J, Boysen G. Stroke incidence and prevalence in Europe: a review of available data. Eur J Neurol 2006;13:581-598.

8. Lavados PM, Sacks C, Prina L, et al. Incidence, 30-day case-fatality rate, and prognosis of stroke in Iquique, Chile: a 2-year community-based prospective study (PISCIS project). Lancet 2005;365:2206-2215.

9. Feigin VL, Lawes CM, Bennett DA, Anderson CS. Stroke epidemiolo- gy: a review of population-based studies of incidence, prevalence, and case-fatality in the late 20th century. Lancet Neurol 2003;2:43-53.

10. Ala L, Gill G, Gurgel R, Cuevas L. Evidence for affluence-related hypertension in urban Brazil. J Hum Hypertens 2004;18:775-779.

11. Anuário Estatístico de Saúde do Brasil 2001 [homepage on the internet]. Brasília: Ministério da Saúde, [cited 2007 Jan 16]. Available from: http:// portal.saude.gov.br/portal/aplicacoes/anuario2001/index.cfm

12. Andre C, Curioni CC, Braga da CC, Veras R. Progressive decline in stroke mortality in Brazil from 1980 to 1982, 1990 to 1992, and 2000 to 2002. Stroke 2006;37:2784-2789.

13. Adams Jr HP, Bendixen BH, Kappelle LJ, et al. Classification of subtype of acute ischemic stroke. Definitions for use in a multicenter clinical trial. TOAST. Trial of Org 10172 in Acute Stroke Treatment. Stroke 1993;24:35-41.

14. Saposnik G, Gonzalez L, Lepera S, et al. Southern Buenos Aires stroke project. Acta Neurol Scand 2001;104:130-135.

15. Saposnik G, Del Brutto OH. Stroke in South America: a systematic review of incidence, prevalence, and stroke subtypes. Stroke 2003;34:2103-2107.

16. Neal B, MacMahon S, Chapman N. Effects of ACE inhibitors, calcium antagonists, and other blood-pressure-lowering drugs: results of prospectively designed overviews of randomised trials. Blood Pressure Lowering Treatment Trialists' Collaboration. Lancet 2000;356:1955-1964.

17. Sichieri R, Coitinho DC, Leao MM, Recine E, Everhart JE. High temporal, geographic, and income variation in body mass index among adults in Brazil. Am J Public Health 1994;84:793-798.

18. Collins R, MacMahon S. Blood pressure, antihypertensive drug treatment and the risks of stroke and of coronary heart disease. Br Med Bull 1994;50:272-298.

19. Donnan GA, Davis SM, Thrift A. The role of blood pressure lowering before and after stroke. Curr Opin Neurol 2003;16:81-86.

20. Donnan GA. PROGRESS results: implementation in stroke guidelines. J Hypertens 2003;(Suppl 21):S25-S28.

21. Randomised trial of a perindopril-based blood-pressure-lowering regimen among 6,105 individuals with previous stroke or transient ischaemic attack. Lancet 2001;358:1033-1041.

22. Ariesen MJ, Claus SP, Rinkel GJ, Algra A. Risk factors for intracerebral hemorrhage in the general population: a systematic review. Stroke 2003;34:2060-2065.

23. Radanovic M. [Characteristics of care to patients with stroke in a secondary hospital]. Arq Neuropsiquiatr 2000;58:99-106.

24. Smadja D, Cabre P, May F, et al. ERMANCIA: epidemiology of stroke in Martinique, French West Indies: Part I. Methodology, incidence, and 30-day case fatality rate. Stroke 2001;32:2741-2747.

25. Cabral LN, Longo LA, Moro CHC, Amaral CH, Kiss HC. [Epidemiology of cerebrovascular disease in Joinville, Brazil: an institutional study]. Arq Neuropsiquiatr 1997;55:357-363. 